\title{
Occupational Segregation and the Gender Wage Gap in Private- and Public-Sector Employment: A Distributional Analysis*
}

\author{
JUAN D. BARÓN \\ Australian National University, Canberra, ACT, \\ Australia and Banco de la República (Central \\ Bank of Colombia), Cartagena de Indias, \\ Colombia
}

\author{
DEBORAH A. COBB-CLARK \\ Australian National University, Canberra, ACT, \\ Australia and Institute for the Study of Labor \\ (IZA), Bonn, Germany
}

We use the Household, Income and Labour Dynamics in Australia data from 2001 to 2006 to analyse the source of the gender wage gap across public- and private-sector wage distributions in Australia. We are particularly interested in the role of gender segregation within sector-specific occupations in explaining relative wages. We find that, irrespective of labour market sector, the gender wage gap among low-paid, Australian workers is more than explained by differences in wage-related characteristics. The gender wage gap among high-wage workers, however, is largely unexplained in both sectors suggesting that glass ceilings (rather than sticky floors) may be prevalent. Gender differences in employment across occupations advantage (rather than disadvantage) all women except those in high-paid jobs, whereas disparity in labour market experience plays a much more important role in explaining relative private-sector wages. Finally, disparity in educational qualifications and demographic characteristics are generally unimportant in explaining the gender wage gap.

\section{Introduction}

After decades of analysing the mean gender wage gap, economists have only recently con- sidered how relative wages differ among highand low-wage workers. It is now clear that the gender wage gap is generally not constant

\footnotetext{
* The authors thank Gigi Foster, Roger Koenker and participants at the 2005 Labour Econometrics Workshop and the Economic Seminar Series at the Australian National University for helpful suggestions and comments. This article uses unit record data from the Household, Income and Labour Dynamics in Australia (HILDA) Survey. The HILDA Project was initiated and is funded by the Australian Government Department of Families, Housing, Community Services and Indigenous Affairs (FaHCSIA) and is managed by the Melbourne Institute of Applied Economic and Social Research (MIAESR). The findings and views reported in this article, however, are those of the authors and should not be attributed to either FaHCSIA, the MIAESR, the Banco de la República (Central Bank of Colombia) or its Board of Directors.

JEL classification: J31, J70, J24

Correspondence: Juan D. Barón, Calle 33 No. 3-123, Centro, Banco de la República, Cartagena de Indias, Colombia. Email: jbaronri@banrep.gov.co
} 
across the entire distribution and that the mean wage gap obscures a great deal of interesting variation in the data. Moreover, a much richer story about the role of gender in the labour market emerges once we move away from an exclusive focus on outcomes for 'average' men and women. In particular, the extent to which disparity in men's and women's productivityrelated characteristics can account for the gender wage gap also appears to differ between high- and low-wage workers. ${ }^{1}$ This implies that our theoretical models of labour market discrimination-and the public policies we adopt to deal with this problem-must be flexible enough to account for the full range of women's experiences both at the top and bottom of the wage distribution.

Men's and women's relative wages also vary across labour market sectors. The mean gender wage gap is often smaller in public-sector jobs (Gunderson, 1989; Gregory \& Borland, 1999; Arulampalam et al., 2007) and the relative wage distribution varies dramatically across sectors (Kee, 2006; Arulampalam et al., 2007). These differences in wage structure are perhaps not surprising given that wage setting in the public sector occurs in a political rather than market environment (Gregory \& Borland, 1999). Additionally, occupational integration appears to be more rapid in public-sector employment, perhaps because antidiscrimination legislation is often more aggressively enforced there. Public-sector jobs are also often concentrated in larger establishments, in specific industries or in certain occupations and employ relatively educated workers. Finally, public-sector employment may attract more risk-averse workers (Pfeifer, 2008).

This article contributes to our understanding of gender wage gaps in Australia by analysing the effect of occupational segregation on relative wages in both public- and private-sector employment. Specifically, how important are

\footnotetext{
${ }^{1}$ García et al. (2001) argue that the unequal size of the discrimination effect across the distribution is related to the inability of traditional measures to fully capture discrimination. In particular, they point to the work of Kuhn (1987) (and others) suggesting that women's perceptions of discrimination do not correspond to traditional statistical measures of discrimination and that women at the top of the wage distribution are more likely to feel that they had been victims of discrimination.
}

gender differences in demographic and human capital characteristics in explaining the gender wage gap in public- and private-sector jobs? Does occupational segregation account for the pattern of relative wages in the two sectors? We make three important contributions to the existing literature. First, our explicit focus on the link between occupational segregation and relative wages across sectors of the Australian labour market is important in light of the emerging international evidence that the gender wage gap stems in large part from the differential return to job status and labour market position (e.g. García et al., 2001; Breunig \& Rospabe, 2005; Kunze, 2005; Amuedo-Dorantes \& De la Rica, 2006). Ultimately, assessing the importance of phenomena such as 'sticky floors' and 'glass ceilings' will rest upon our understanding of the way that labour market position affects men's and women's employment outcomes more generally. Second, pooling waves 1-6 of Household, Income and Labour Dynamics in Australia (HILDA) data allows us to control for gender differences in employment across very detailed, sector-specific occupations. ${ }^{2}$ Finally, we adopt the semiparametric methodology proposed by DiNardo et al. (1996), which enables us to explicitly decompose public- and private-sector gender wage gaps into their various components at multiple points of the wage distribution. While Kee (2006) analysed only the overall 'explained' component, we can assess the relative importance of a variety of factors (specifically, demographics, educational qualifications, experience and labour market position) in producing the gender wage gap.

We find that, irrespective of labour market sector, the gender wage gap among low-paid, Australian workers is more than explained by differences in wage-related characteristics. The gender wage gap among high-wage workers, however, is largely unexplained in both sectors suggesting that glass ceilings (rather than sticky floors) may be prevalent. Gender differences in employment across occupations advantage (rather than disadvantage) all women except those in high-paid jobs, while disparity in

\footnotetext{
${ }^{2}$ Previous researchers have generally focused on aggregate occupations. For example, Kee (2006) accounts for 18 occupations. Our analysis controls for gender differences in 40 public- and 64 private-sector occupations.
} 
labour market experience plays a much more important role in explaining relative privatesector wages. Finally, disparity in educational qualifications and demographic characteristics are generally unimportant in explaining the gender wage gap.

\section{Gender Wage Gaps in Australia}

Forty years after the 1969 Equal Pay Case there continues to be a substantial gap in the wages of Australian men and women. ${ }^{3}$ This disparity stems primarily from differential returns to productivity-related characteristics which is consistent with labour market discrimination. Women's relative wages are lower amongst the self-employed (Eastough \& Miller, 2004), at the top of the wage distribution (Miller 2005; Kee, 2006) and differ substantially across labour market sectors (Kee, 2006). Although the international literature finds that much of the gender wage gap is explained by segregation across occupations, industries or jobs (see, e.g. Groshen, 1991; Blau \& Kahn, 2000), it is less obvious that segregation can account for the gender wage gap in Australia (Miller, 1987; Rimmer, 1991; Kidd, 1993; Lee \& Miller, 2004). Rimmer (1991) and Lee \& Miller (2004) conclude, for example, that women's relative earnings would fall rather than rise if they had the same occupational distribution as men. Similarly, Kee (2006) finds little difference in results which do and do not control for industry and occupation leading her to conclude that segregation does not seem to be the major driver of the gender wage gap. ${ }^{4}$ These patterns are particularly striking given the evidence that occupational segregation has fallen substantially in the United States (Blau \& Kahn 2000), whereas the integration of occupations in Australia appears to have been modest at best (Rimmer, 1991; Lee \& Miller, 2004).

Despite this previous literature, there remains much we do not know about the effect of segregation on relative wages. Kee (2006) controls only for aggregated occupations-a strategy

\footnotetext{
${ }^{3}$ See Rummery (1992), Borland (1999), and Eastough and Miller (2004) for extensive reviews.

${ }^{4}$ In contrast, Kidd and Shannon (1996), using the decomposition proposed by Juhn et al. (1991), found that controlling for both industry and occupation reduced the unexplained component of the Australian gender wage gap by 13 per cent.
}

which Gunderson (1989) argues increases the risk of under-estimating the effect of occupational segregation. Moreover, it is unclear what these patterns imply about labour market discrimination per se. The simple inclusion of occupation controls in wage regressions designed to measure labour market discrimination is appropriate only to the extent that gender segregation stems from individuals' unobserved human capital or job preferences rather than from discriminatory factors (see e.g. Miller, 1987; Arulampalam et al., 2007). In particular, Arulampalam et al. (2007) argue that estimates of the gender pay gap with and without such controls provide lower and upper bounds on the extent of discrimination. ${ }^{5}$ Our results suggest, however, that this reasoning may be inappropriate in Australia where women appear to be advantaged rather than disadvantaged by their occupational distribution.

\section{Data}

\section{(i) The HILDA Survey}

The data come from the HILDA Survey. ${ }^{6}$ Unlike Miller (2005) who analyses data from the 2001 Australian Census and Kee (2006) who analyses wave 1 HILDA data, we pool HILDA data from waves 1 to 6 spanning the period from 2001 to $2006 .^{7}$ The advantage of HILDA data for our purposes is that they provide more detailed information about individuals' demographic characteristics, occupational classification and labour market experience than do census data. Pooling data across waves makes our results more robust to particular events affecting the labour market in specific years, improves the precision of our

\footnotetext{
${ }^{5}$ See also Shapiro and Stelcner (1981) who make a similar distinction between a narrow definition of discrimination as unequal pay for equal work and a broader view that considers all forms of labour market discrimination.

${ }^{6}$ Wave 1 included 13,969 respondents aged 15 and older distributed across 7682 households.

${ }^{7}$ We use the Stata add-on package PanelWhiz v2.0 (November 2007) for verifying the availability and consistency of coding for some variables in HILDA. PanelWhiz was written by Dr John P. Haisken-DeNew (john@panelwhiz.eu; see Haisken-DeNew \& Hahn, 2006).
} 
estimates and reduces concerns about sample selection. ${ }^{8}$

Our analysis sample includes private- and public-sector employees between the ages of 22 and 60 years. We make this age restriction to exclude individuals in study-to-work and workto-retirement transitions. We also exclude the self-employed and those drawing a salary from their own business. To avoid outliers, we exclude people in the top and bottom 1 per cent of the gender-specific wage distribution. Our estimation sample therefore represents individuals who are present-and satisfy all the selection criteria-in at least one wave of HILDA. The sample in wave 1 , for example, consists of 608 men and 842 women in the public sector and 1852 men and 1426 women in the private sector. In the entire sample there are 4278 men and 4190 women with a total of 25,982 personyear observations.

The dependent variable in our analysis is the hourly wage rate in the main job. It is calculated as the ratio of current weekly gross wages and the number of hours usually worked per week, both measured in the individual's main job. We use the consumer price index (CPI) available from the Australian Bureau of Statistics (ABS; 2008) to deflate wages to 2001 levels. ${ }^{9}$ Following Arulampalam et al. (2007) and Kee (2006), we analyse the determinants of the gender wage gap separately for public- and private-sector employment. People are classified as working in the public sector if they report that the best description of their employer (or business) is a government business enterprise or commercial statutory authority, or other governmental organisation (i.e. public service departments, local councils, schools or universities). People classified as private-sector workers describe their

\footnotetext{
${ }^{8}$ There are many reasons to assume that there is an individual-specific error component in the wage model. Given this, pooling is potentially useful in reducing sample selection bias because it allows us to observe a larger fraction of the population. Wavespecific participation rates for HILDA respondents aged 22-60 range from 57.6 to 66.2 per cent for men and from 48.4 to 54.0 per cent for women. However, 92.7 per cent of men and 82.1 per cent of women in this age range are labour market participants in the pooled HILDA sample.

${ }^{9}$ Specifically, we use the CPI at the end of the second quarter of each year, for all groups of goods, calculated as the weighted average of eight capital cities.
}

employer as being a private, for-profit organisation. Those working for private not-for-profit, other commercial and other non-commercial organisations are excluded from the analysis.

We include controls for demographic characteristics (e.g. marital status, age, immigration status), human capital characteristics (e.g. education, employer tenure, occupation tenure and labour market experience), state or territory of residence and job characteristics (e.g. firm size, industry, part-time status, union membership and occupation). One advantage of HILDA data relative to census data is that they provide us with measures of actual labour market experience as well as both employer and occupation tenure. These measures are much more useful than potential experience measures in characterising the labour market histories of women. HILDA also provides detailed occupational information. Our measure of occupation is based upon combining sub-major groups in the Australian Standard Classification of Occupations (ASCO), second edition, and the ANU4 scale (Jones \& McMillan, 2001). At this ASCO level, there are 35 occupations ranging from several managerial occupations to cleaners and labourers (ABS, 1997). Using the ANU4 scale to further disaggregate two-digit ASCO occupations we obtain 40 occupational categories for the public sector and 64 for the private sector. Descriptive statistics are presented by gender and sector in Appendix Table A1.

Not surprisingly, there are several differences in the relative characteristics of men and women both within and across sectors. Proportionately more men than women employed in the public sector are married, whereas there is no substantial gender difference in marriage rates in the private sector. In both sectors, divorced women represent a larger proportion of employees than divorced men. On average, there is a one-year age difference between men and women in the public sector but there is virtually no age difference in the private sector. Women in the public sector are more likely than men to have a bachelor degree or above. In terms of experience, women have almost three fewer years tenure with their current employer in the public sector, but only one less year in the private sector. Our other measures of experience, tenure in current occupation and time in the labour force since full-time education, also exhibit similar gender differences. Finally, irrespective of labour market sector, women are more likely than men to 
TABLE 1

Unconditional Gender Wage Gap across the Wage Distribution by Sector (in 2001 Dollars)

\begin{tabular}{|c|c|c|c|c|c|c|}
\hline & \multicolumn{3}{|c|}{ Wages in public sector } & \multicolumn{3}{|c|}{ Wages in private sector } \\
\hline & Woman & Man & Wage gap & Woman & Man & Wage gap \\
\hline Mean & $\begin{array}{c}20.96 \\
(0.20)\end{array}$ & $\begin{array}{c}23.82 \\
(0.29)\end{array}$ & $\begin{array}{c}2.86 \\
(0.35)\end{array}$ & $\begin{array}{l}17.20 \\
(0.16)\end{array}$ & $\begin{array}{l}20.82 \\
(0.19)\end{array}$ & $\begin{array}{c}3.62 \\
(0.24)\end{array}$ \\
\hline 10th percentile & $\begin{array}{l}13.01 \\
(0.18)\end{array}$ & $\begin{array}{l}14.78 \\
(0.28)\end{array}$ & $\begin{array}{l}1.77 \\
(0.33)\end{array}$ & $\begin{array}{l}10.96 \\
(0.12)\end{array}$ & $\begin{array}{l}11.88 \\
(0.11)\end{array}$ & $\begin{array}{c}0.92 \\
(0.16)\end{array}$ \\
\hline 25 th percentile & $\begin{array}{l}15.78 \\
(0.19)\end{array}$ & $\begin{array}{l}18.07 \\
(0.27)\end{array}$ & $\begin{array}{l}2.28 \\
(0.33)\end{array}$ & $\begin{array}{l}13.07 \\
(0.08)\end{array}$ & $\begin{array}{l}14.44 \\
(0.12)\end{array}$ & $\begin{array}{l}1.37 \\
(0.15)\end{array}$ \\
\hline Median & $\begin{array}{l}19.97 \\
(0.23)\end{array}$ & $\begin{array}{l}22.60 \\
(0.28)\end{array}$ & $\begin{array}{c}2.64 \\
(0.36)\end{array}$ & $\begin{array}{l}15.52 \\
(0.11)\end{array}$ & $\begin{array}{l}18.23 \\
(0.19)\end{array}$ & $\begin{array}{c}2.71 \\
(0.22)\end{array}$ \\
\hline 75th percentile & $\begin{array}{l}24.87 \\
(0.28)\end{array}$ & $\begin{array}{c}28.05 \\
(0.35)\end{array}$ & $\begin{array}{l}3.19 \\
(0.45)\end{array}$ & $\begin{array}{l}19.37 \\
(0.24)\end{array}$ & $\begin{array}{l}24.40 \\
(0.34)\end{array}$ & $\begin{array}{c}5.03 \\
(0.42)\end{array}$ \\
\hline 90th percentile & $\begin{array}{l}30.05 \\
(0.36)\end{array}$ & $\begin{array}{c}34.23 \\
(0.66)\end{array}$ & $\begin{array}{c}4.18 \\
(0.75)\end{array}$ & $\begin{array}{c}25.29 \\
(0.43)\end{array}$ & $\begin{array}{l}33.56 \\
(0.59)\end{array}$ & $\begin{array}{c}8.27 \\
(0.74)\end{array}$ \\
\hline
\end{tabular}

Notes: The sample includes employees aged 22-60 receiving wages in each wave. We use data from the Household, Income and Labour Dynamics in Australia waves 1-6. We use the consumer price index to transform wages to 2001 dollars. Wages per hour are calculated as the ratio between current weekly gross wage and salary to hours per week usually worked both in the main job. The numbers in parentheses are bootstrapped standard errors with 5000 replications. Standard errors are clustered at the individual level. All statistics in the table are statistically different from zero at the 1 per cent level. There are 4132 women and 4181 men in the sample, with 25,982 person-year observations. Population weights were used in the calculations.

work in jobs that are part-time, casual or in organisations with less than 100 employees (see Appendix Table A1).

(ii) Gender Differences in Pay: Does the Level of Pay Matter?

Table 1 reports wage levels (in 2001 AUD) both at the mean and at the 10th, 25th, 50th, 75 th and 90th percentiles of the wage distribution separately by gender and labour market sector. Standard errors have been bootstrapped (with 5000 repetitions) to account for the dependency among observations arising from the fact that we have multiple observations per individual. Specifically in Table 1 -and in all of our subsequent results-we implement the bootstrap by sampling with replacement individuals rather than observations. ${ }^{10}$ The results indicate that on average the women in our sample who are employed in the public sector earn almost $\$ 3.00$ less per hour than men ( $\$ 20.96$ versus $\$ 23.82$ per hour). The gender wage gap is somewhat larger in the private sector (\$3.62) despite the fact that average hourly wages are lower for both men (\$20.82) and women (\$17.20). As expected, however, average wages tell us very

\footnotetext{
${ }^{10}$ We thank Roger Koenker for this suggestion.
}

little about the size of the gender wage gap among low- versus high-wage earners. Although there is a statistically significant difference in men's and women's wages at all points of the wage distribution, we find that the gender wage gap is much larger amongst high-wage workers, particularly in the private sector. Moreover, the mean gender wage gap is also larger than that at the median which is consistent with the typical skewness in wage distributions.

Although Table 1 presents information about the gender wage gap in levels, it is also useful to consider relative wages. Figure 1 shows the natural logarithm of the ratio of male to female wages at each percentile of the wage distribution for both the public and private sectors. We have trimmed the bottom and top 5 per cent of the wage distribution because of the high variability of these observations. Figure 1 also shows normal confidence intervals at the 95 per cent level using the same bootstrapping method described before. We find that relative wages are roughly constant across the distribution of public-sector wages with minor variation at some percentiles (see Fig. 1). Men employed in the public sector earn approximately 12.5 per cent more than women irrespective of whether they are high- or low-wage workers. In the private sector, however, the wage gap increases as 
FIGURE 1

Natural Logarithm of the Gender Wage Ratio by Sector

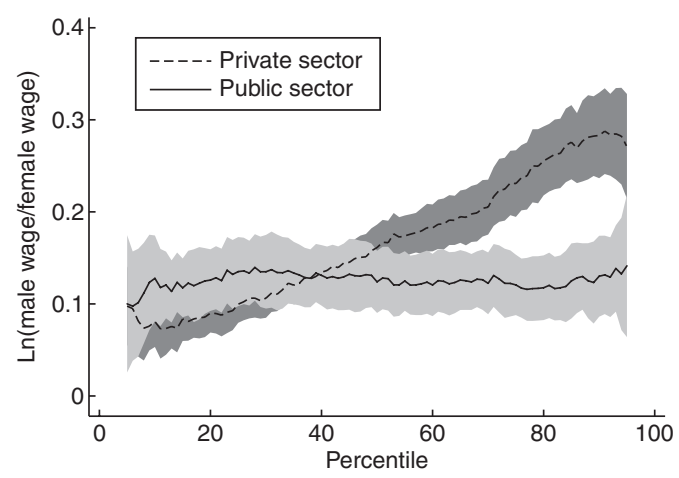

Notes: The sample includes employees aged 22-60 receiving wages in each wave. We use data from the Household, Income and Labour Dynamics in Australia waves 1-6. We use the consumer price index to transform wages to 2001 dollars. Wages per hour are calculated as the ratio between current weekly gross wage and salary to hours per week usually worked both in the main job. The bands represent bootstrapped normal confidence intervals at the 95 per cent level with 5000 replications and clustered at the individual level. The graph excludes the top and bottom five percentiles. The dashed and solid lines represent the difference between women's and men's natural logarithm of the wage per hour (at each percentile, 2001 dollars). There are 4132 women and 4181 men in the sample, with 25,982 person-year observations. Population weights were used in the calculations.

one moves up the wage distribution. Women at the 10th percentile face a wage gap of 8.1 per cent, whereas the wage gap at the 90th percentile rises to 28.3 per cent. At the bottom of the wage distribution, the relative wage of women is significantly higher in the public sector than in the private sector, whereas at the top of the wage distribution the reverse is true. Relative wages do not differ significantly across sectors in the middle of the distribution (i.e. between approximately the 35th and 60th quantiles). These results are consistent with Miller (2005) and Kee (2006).

\section{(iii) Gender Wage Gaps and Occupational Segregation in Australia}

Does occupational segregation account for the pattern of relative wages in the two sectors? We address this question by comparing the proportion of employed men and women in each ASCO major group (see Fig. 2). Despite aggregating into only nine occupations, we observe a high degree of segregation in middleskill jobs in intermediate production and transport occupations; intermediate clerical, sales and services occupations; and trade occupations. This is not particularly surprising as these classifications include jobs such as plant operators and drivers; clerks, receptionists and carers; and electricians, mechanics and plumbers. More skilled occupations also show a high degree of gender segregation in the public sector: slightly less than half of the women in our sample are categorised as professionals compared with only 33.1 per cent of men. Professionals include nurses, teachers and social welfare workers. In contrast, women are under-represented in highskilled managerial and administrative occupations. Fully, 8.7 per cent of men work in these occupations in comparison with 4.7 per cent of women. Segregation (as measured by the difference in proportion of men and women working in specific occupations) appears to be higher in the private sector. Men are almost 2.5 times as likely as women to be in a managerial or administrative occupation and equally as likely to be a professional. Women are substantially overrepresented in clerical and service jobs and under-represented in production and transport jobs in the private sector.

The differences across major occupational grouping are likely to provide a conservative estimate of the degree of gender segregation in the Australian labour market generally (see Gunderson, 1989). Moreover, they represent aggregate statistics across all workers and tell us nothing about how occupational segregation varies across wage levels. We investigate this issue by assessing the extent of gender segregation among high- and low-wage workers using an index of dissimilarity among detailed occupations at different levels of pay separately by sector (see Fig. 3). Specifically, we classify men and women into six wage groups: (i) those in the bottom 10 per cent of their respective gender-specific wage distribution; (ii) those earning wages between the 10th and 25 th percentiles; (iii) those between the 25 th percentile and the median; (iv) those between the median and the 75 th percentile; (v) those between the 75th and 90th percentiles; and (vi) those earning wages in the top 10th percentile. For each of these sub-samples of individuals, we then calculate an index of occupational segregation as: 
FIGURE 2

Occupational Segregation by Gender, Sector and Major Australian Standard Classification of Occupation (ASCO) Groups. (a) Public Sector; (b) Private Sector

(a)

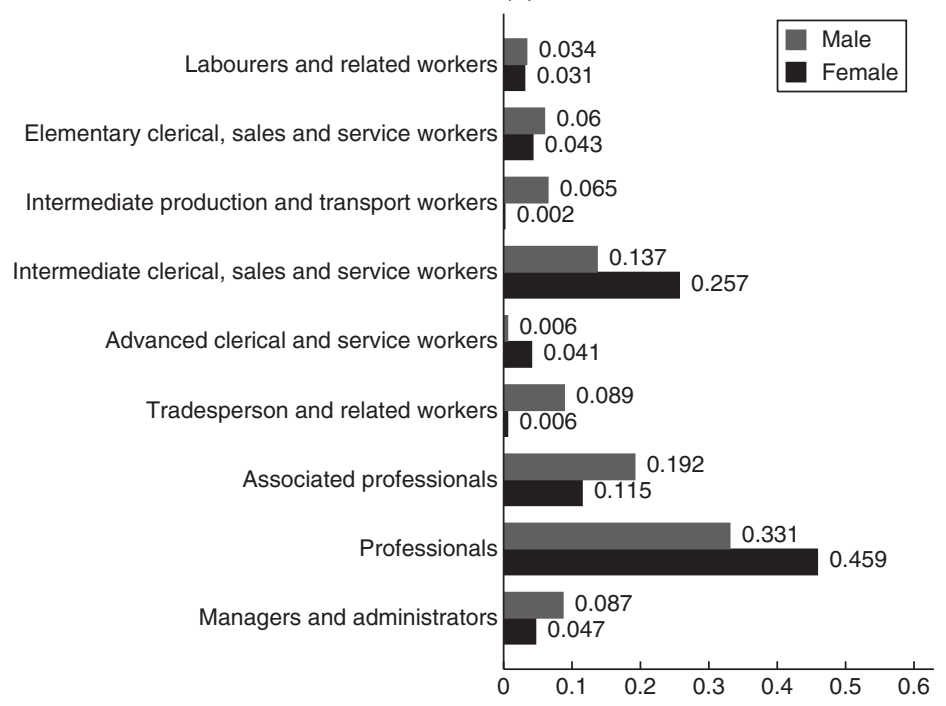

(b)

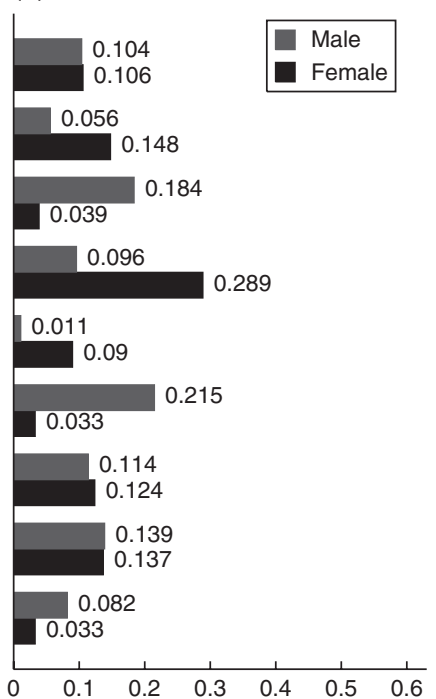

Notes: Occupations are the ASCO's major groups (nine categories). There are 4132 women and 4181 men in the total sample, with 25,982 person-year observations. Population weights were used in the calculations.

$$
\mathrm{ID}_{i}=\frac{1}{2} \sum_{j}\left|M_{i j}-F_{i j}\right|,
$$

where $i=1,2, \ldots, 6$ indexes our segments of the wage distribution and $M_{i j}$ and $F_{i j}$ are the proportions of total men and women working in occupation $j$. Here we use detailed occupation groups; so, $j=1,2, \ldots, 40$ in the public sector and $j=1,2, \ldots, 64$ in the private sector. ${ }^{11}$ For each wage group $i$, this index tells us the proportion of male or female workers who would have to change jobs to make the gender alloca-

\footnotetext{
${ }^{11}$ These occupations are based on sub-major group in the ASCO, second edition (ABS, 1997) and the ANU4 classification (Jones \& McMillan, 2001). At this level of ASCO aggregation there are 35 occupations. By using the ANU4 scale we are able to disaggregate some of the ASCO2 categories even further. We also excluded from the analysis 100 person-year observations corresponding to the sub-group Farmers and Farmer Managers (13). See Appendix Tables A2 and $\mathrm{A} 3$ for a detailed list of occupations in the analysis in the public and private sectors.
}

tion of jobs the same. ID $_{i}$ equals zero if the distribution of jobs is exactly the same across genders, and equals one if men are employed in completely different jobs to the ones employing women (see, e.g. Dolado et al., 2002).

We find that occupational segregation in the public sector varies substantially across the distribution of wages (Fig. 3). The index of segregation suggests that as many as 52 per cent of individuals would have to change occupations to make the gender distribution of low-wage jobs in the public sector identical across genders. At the top of the public-sector wage distribution, the segregation index is 43 per cent. In the public sector, there is a negative relationship between wage levels and the degree of occupational segregation. Interestingly, the degree of occupational segregation increases with wages in the private sector, particularly in the bottom half of the wage distribution. ${ }^{12}$

\footnotetext{
${ }^{12}$ The dissimilarity index calculated across all workers using our detailed classification in the public and private sectors is 0.429 and 0.532 , respectively.
} 
Figure 3

Occupational Segregation across the Distribution of Wages, by Sector

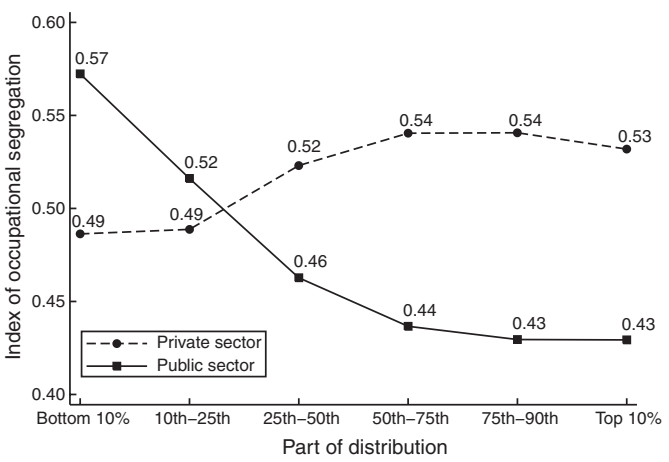

Notes: The figures represented in this graph are calculated as follows: we calculate the proportion of total women and total men working in each occupation for individuals at different points of the wage distribution (e.g. in the bottom 10 per cent of their corresponding gender wage distribution). At each of these points of the distribution, and for each sector, we calculate an index of occupational segregation as ID = $0.5 \times \sum_{i}\left|M_{i}-F_{i}\right|$, where $i$ indexes occupations, and $M_{i}$ and $F_{i}$ are the proportions of total men and total women in occupation $i$. The resulting statistic tells us the proportion of women or men workers who would have to change jobs to make the distribution of occupations for each gender identical. The occupations used are based on the Australian Standard Classification of Occupations' sub-major groups and the ANU4 (40 categories in the public sector and 64 in the private sector). See Tables A2 and A3 for a detailed description of occupations in each sector. There are 4132 women and 4181 men in the sample, with 25,982 personyear observations.

The question that remains is: How does occupational segregation affect the distribution of the gender wage gap across sectors? In what follows, we address this issue by accounting for detailed occupations in our decomposition of the gender wage gap across the distribution. Given the different evolution of wage gaps in the public and private sectors in both absolute and relative terms, we present our decomposition results for each sector separately.

\section{Econometric Method}

We adopt the semi-parametric methodology proposed by DiNardo et al. (1996) to decompose the distribution of the gender wage gap into its separate components. We begin by assuming that each observation in the sample is drawn from the joint distribution $f(w, \mathbf{x}, g)$, where $w$ represents the wage rate, $\mathbf{x}$ is a vector of wage covariates (e.g. education level, experience, etc.) and $g$ is gender ( 0 for men and 1 for women). Conditional on gender $g$, we can write the joint distribution of wages and covariates as the conditional distribution $f(w, \mathbf{x} \mid g)$. This implies that the distribution of men's wages $f^{0}(w)$ is defined as the integral of the conditional density of wages over the domain of individuals' wage-related characteristics $\left(\Omega_{\mathbf{x}}\right)$ :

$$
f^{0}(w)=\int_{\mathbf{x} \in \Omega_{\mathbf{x}}} f(w, \mathbf{x} \mid g=0) \mathrm{d} \mathbf{x} .
$$

The definition of a conditional density implies that Equation (2) can be rewritten as:

$$
f^{0}(w)=\int_{\mathbf{x} \in \Omega_{\mathbf{x}}} f(w \mid \mathbf{x}, g=0) f_{\mathbf{x}}(\mathbf{x} \mid g=0) \mathrm{d} \mathbf{x},
$$

where $f(\cdot)$ is the distribution of wages conditional on both characteristics and being men and $f_{\mathbf{x}}(\cdot)$ is the distribution of wage covariates among men. The density of women's wages is defined analogously.

This representation of the (marginal) distribution of wages is useful in creating a series of counterfactual wage distributions which allow the effects of the various factors driving the gender wage gap to be isolated. Specifically, we partition the vector of wage covariates $(\mathbf{x})$ into the following four components: (i) labour market position (l); (ii) experience (e); (iii) educational attainment (h); and (iv) demographic characteristics $(d)$. We focus on these components specifically because previous research suggests that these are the main drivers of gender wage inequality. This partitioning, $\quad \mathbf{x}=[l, e, h, d]$, allows us to write the wage distribution for men as: ${ }^{13}$

$$
\begin{aligned}
f^{0}(w)= & \int_{l} \int_{e} \int_{h} \int_{d} f(w, l, e, h, d \mid g=0) \\
& \cdot \mathrm{d} l \cdot \mathrm{d} e \cdot \mathrm{d} h \cdot \mathrm{d} d
\end{aligned}
$$

or

\footnotetext{
${ }^{13}$ Note that although some of the wage components contain only indicator variables, for simplicity we have used the notation for continuous random variables consistently throughout.
} 


$$
\begin{aligned}
f^{0}(w)= & \int_{l} \int_{e} \int_{h} \int_{d} f(w \mid l, e, h, d, g=0) \\
& \cdot f_{l}(l \mid e, h, d, g=0) \cdot f_{e}(e \mid h, d, g=0) \\
& \cdot f_{h}(h \mid d, g=0) \cdot f_{d}(d \mid g=0) \\
& \cdot \mathrm{d} l \cdot \mathrm{d} e \cdot \mathrm{d} h \cdot \mathrm{d} d .
\end{aligned}
$$

Equation (5) is composed of five (conditional) probability densities. Note that $f$ is the conditional wage density given all wage covariates (x) and being men $(g=0)$, whereas $f_{l}$ is the conditional density of labour market position given experience, educational qualifications, demographic characteristics and gender. In the same way, $f_{e}$ and $f_{h}$ represent the conditional densities of experience and educational qualifications. Finally, $f_{d}$ reflects the density of demographic characteristics conditional on gender. When the conditional expectations of these densities are linear in their arguments, we can think of $\mathbf{x}$ as reflecting a set of wage determinants, $[e, h, d]$ as capturing the determinants of labour market position and so on (Butcher \& DiNardo, 2002). To facilitate the interpretation of the decomposition, we partition $\mathbf{x}=[l, e, h, d]$ in such a way that more 'endogenous' variables are conditional upon less 'endogenous' variables (Cobb-Clark \& Hildebrand, 2006).

The advantage of expressing the male wage distribution as in Equation (5) is that counterfactual distributions arise intuitively. We can obtain, for example, the counterfactual wage distribution that would prevail if men retained their own conditional distributions of experience, educational qualifications and demographic characteristics; but had the same conditional distribution of labour market position as women. That is,

$$
\begin{aligned}
f^{A}(w)= & \int_{l} \int_{e} \int_{h} \int_{d} f(w \mid l, e, h, d, g=0) \\
& \cdot f_{l}(l \mid e, h, d, g=1) \cdot f_{e}(e \mid h, d, g=0) \\
& \cdot f_{h}(h \mid d, g=0) \cdot f_{d}(d \mid g=0) \\
& \cdot \mathrm{d} l \cdot \mathrm{d} e \cdot \mathrm{d} h \cdot \mathrm{d} d .
\end{aligned}
$$

We can then compare the counterfactual distribution given by $f^{A}$ with another counterfactual distribution $\left(f^{B}\right)$ in which men retain their own educational qualifications and demographic characteristics, but have the same labour market position and experience distributions as women. Similarly, $f^{C}$ is the counterfactual wage distribution when men retain only their demographic characteristics, whereas $f^{D}$ is the counterfactual wage density that results from assigning women's distributions for all four sets of wage covariates to men.

Using these counterfactual wage distributions and the observed wages for men and women, we can decompose the gender wage gap at any quantile of the wage distribution, $q_{i}(\cdot)$, as follows:

$$
\begin{aligned}
& q_{i}\left(f^{0}(w)\right)-q_{i}\left(f^{1}(w)\right) \\
&= {\left[q_{i}\left(f^{0}(w)\right)-q_{i}\left(f^{A}(w)\right)\right]+\left[q_{i}\left(f^{A}(w)\right)\right.} \\
&\left.-q_{i}\left(f^{B}(w)\right)\right]+\left[q_{i}\left(f^{B}(w)\right)-q_{i}\left(f^{C}(w)\right)\right] \\
&+\left[q_{i}\left(f^{C}(w)\right)-q_{i}\left(f^{D}(w)\right)\right]+\left[q_{i}\left(f^{D}(w)\right)\right. \\
&\left.-q_{i}\left(f^{1}(w)\right)\right] .
\end{aligned}
$$

The first term on the right-hand side of Equation (7) captures the part of the gender wage gap, at quantile $q_{i}(\cdot)$, attributable to gender differences in labour market position. The second term represents the component attributable to differences in experience, whereas the third and fourth capture the components attributable to gender differences in educational qualifications and demographic characteristics, respectively. The final term represents differences in the conditional (on $\mathbf{x}$ ) wage distributions of men and women. In particular, it is the portion of the gender wage gap that stems from the disparity in wages received by men and women with the same characteristics. ${ }^{14}$

Implementing this decomposition requires estimating the counterfactual distributions $f^{A}$ to $f^{D}$. The contribution of DiNardo et al. (1996) is

\footnotetext{
${ }^{14}$ This decomposition is not unique. First, we have partitioned the wage covariates into four components implying that there are 4 ! permutations of the decomposition given in Equation (7). To avoid results being driven by one particular decomposition, we estimate all 24 relevant permutations and present results averaged across all of them (Cobb-Clark \& Hildebrand, 2006). Second, this decomposition weights the difference in conditional wage distributions by women's characteristics. It effectively provides an estimate of what women would earn if they retained their own characteristics, but were paid like men. This is consistent with a model of discrimination against women rather than nepotism towards men and is the more interesting counterfactual for our purposes (see Neumark, 1988; Arulampalam et al., 2007). We also estimated the parallel decomposition which weights the differences in returns by male characteristics and found the results broadly consistent with those presented here. Results are available upon request.
} 
to show that counterfactual distributions can be obtained by reweighting the observed wage distribution for either men or women. To see this, rewrite the counterfactual wage distribution $f^{A}$ as:

$$
\begin{aligned}
f^{A}(w)= & \int_{l} \int_{e} \int_{h} \int_{d} \psi_{l} f(w \mid l, e, h, d, g=0) \\
& \cdot f_{l}(l \mid e, h, d, g=0) \cdot f_{e}(e \mid h, d, g=0) \\
& \cdot f_{h}(h \mid d, g=0) \cdot f_{d}(d \mid g=0) \\
& \cdot \mathrm{d} l \cdot \mathrm{d} e \cdot \mathrm{d} h \cdot \mathrm{d} d,
\end{aligned}
$$

where $\quad \psi_{l}=f_{l}(l \mid e, h, d, g=0) / f_{l}(l \mid e, h, d, g=$ 1). A comparison of Equations (5) and (8) reveals that these equations differ only in the reweighting function $\psi_{l}$. Bayes theorem implies that $\psi_{l}$ can be rewritten as:

$$
\begin{aligned}
\psi_{l}= & P(g=0 \mid \mathbf{x}) P(g=1 \mid e, h, d) \\
\cdot & {[P(g=1 \mid \mathbf{x}) P(g=0 \mid e, h, d)]^{-1} . }
\end{aligned}
$$

Note that the calculation of $\psi_{l}$ involves only the probabilities of being man or woman conditional on various sets of wage covariates. We can therefore estimate these probabilities using logit models in which the dependent variable is a gender indicator. These estimated probabilities can then be combined to generate an estimate of the reweighting factor $\left(\psi_{l}\right)$, which then multiplies the observed wage distribution for men to create $f^{A}$. Other counterfactual distributions are calculated in an analogous way.

The method proposed by DiNardo et al. (1996) is by no means the only method for decomposing the gender gap at multiple points of the wage distribution. Alternatives can be found in, among others, Blau and Kahn (1996), Fortin and Lemieux (1998) and Donald et al. (2000). In particular, quantile regression is another recent method that has been used to analyse wage gaps and wage inequality. ${ }^{15}$ Whether the DiNardo et al. (1996) decomposition or decompositions based on quantile regressions produce more precise results has not been addressed in the literature. The selection of the decomposition method depends on the aim of the study. We choose DiNardo et al.'s (1996) decomposition because it is easy to implement

\footnotetext{
${ }^{15}$ For an introduction, see Koenker and Hallock (2001) and Buchinsky (1998). Applications of this methodology to Australian data are available in Miller (2005) and Kee (2006).
}

and because it provides an estimate of the total proportion of the wage gap that can be attributed to various sets of wage determinants. If interest lies in the specific contribution of single covariates (either continuous or discrete) to the gender wage gap, the decomposition approach proposed by Firpo et al. (2007) seems to be a natural extension of DiNardo et al.'s (1996) approach.

\section{$V$ Results}

We are interested in understanding the relative importance of gender differences in demographic characteristics, educational qualifications, experience and labour market position in explaining the distribution of gender wage gaps in both public- and private-sector employment. We investigate this issue using the method described in Section IV to decompose sector-specific gender wage gaps into their relevant components. ${ }^{16} \mathrm{We}$ begin by estimating a model that excludes occupation from the vector of labour market position variables. We then repeat the decomposition exercise adding controls for detailed occupations. In addition to shedding light on how gender segregation within sector-specific occupations affects relative wages in the two sectors, this procedure also gives us insight into the sensitivity of the unexplained component (i.e. estimated labour market discrimination) to alternative assumptions about the discriminatory nature of the occupational distribution itself (see Miller, 1987; Arulampalam et al., 2007). In particular, Arulampalam et al. (2007) argue that estimates of the gender pay gap with and without such controls provide lower and upper bounds on the extent of discrimination.

Table 2 presents results for the decomposition of the logarithm of the ratio of male to female hourly wages in the public sector. Unconditional relative wage ratios are presented in the first column of Table 2, while the subsequent columns show the estimated proportion of this gap that can be attributed to gender differences in each underlying component. Bootstrapped standard errors (with 2000 repetitions) are presented

\footnotetext{
16 The decomposition is performed using the Stata command decompose.ado written by Juan Barón and James Muller. The code is available upon request. Many statistics can also be decomposed with this command.
} 


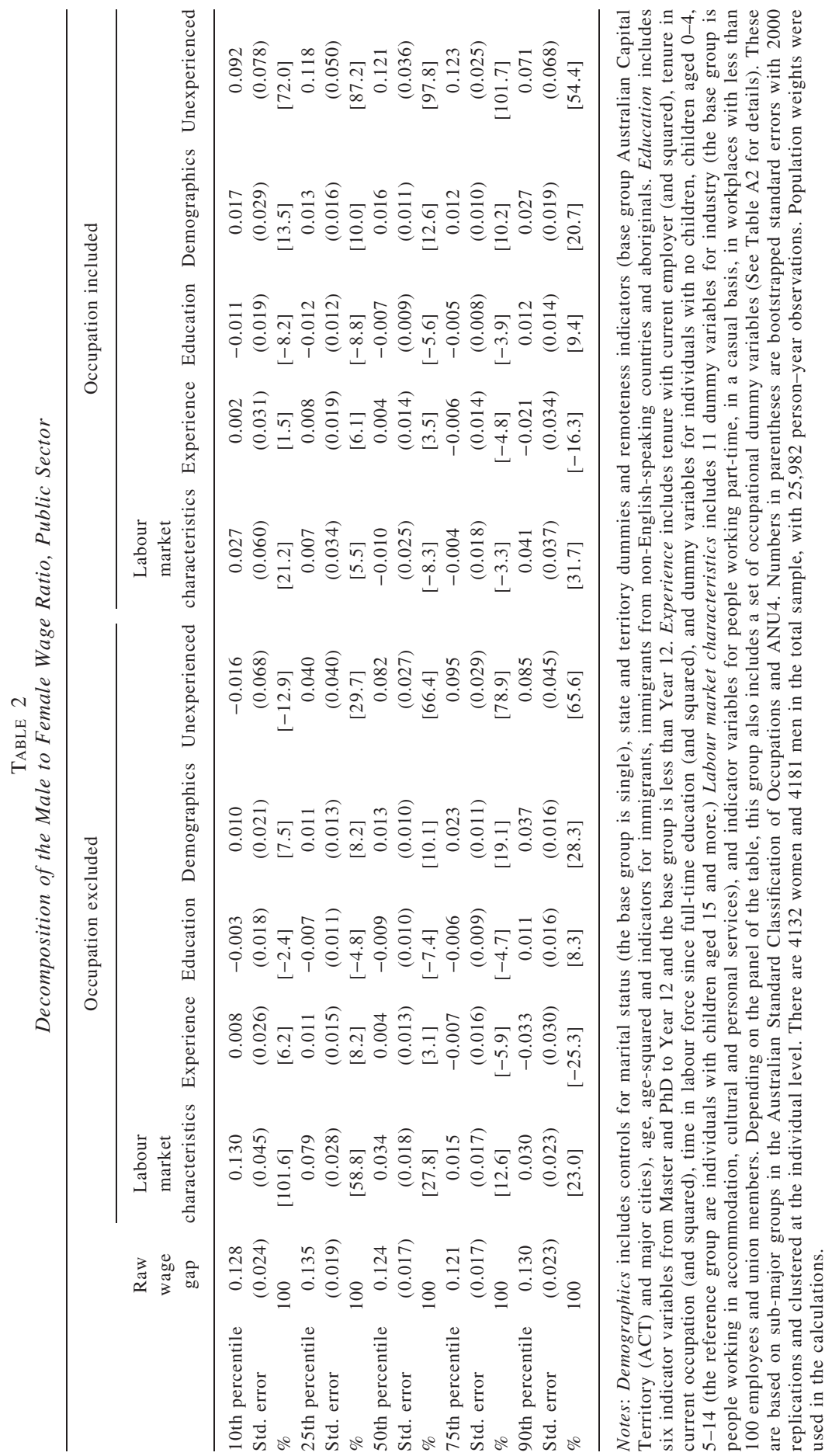


in parentheses. ${ }^{17}$ Finally, the percentage of the wage gap attributable to each factor is shown in brackets.

In the public sector, relative wages are roughly constant with a gender wage gap of approximately 12.5 per cent across the distribution (see Fig. 1). Gender differences in wagerelated characteristics fully account for the lower wages received by women at the bottom of the wage distribution. The proportion of the gender wage gap that cannot be explained by differences in wage-related characteristics (see column 6) is insignificantly different from zero in the bottom half of the distribution. Among high-wage workers, however, the portion of the wage gap not attributable to gender differences in endowments rises to over 60 per cent. Despite the fact that the magnitude of the public-sector gender wage gap is relatively constant, the extent to which it can be explained by the wage-related characteristics of men and women falls as we move up the wage distribution. Overall, it appears that high-wage public-sector employees in Australia may face more employer discrimination (i.e. glass ceilings) than lowwage workers (i.e. sticky floors). Arulampalam et al. (2007) also find no evidence of sticky floors in European public sector employment, while Kee (2006) reaches the same conclusion for Australia.

It is also useful to consider the relative importance of gender differences in specific wagerelated characteristics in producing wage gaps. Our results indicate that at the 10th percentile of the wage distribution, gender differences in labour market position (e.g. industry, casual status, part-time status, union membership) account fully for 101.6 per cent of the gender wage gap. Although the effect of labour market position falls (and becomes insignificant) as we move up the wage distribution, it is a particularly important explanation for the gender wage gap in the bottom half of the wage distribution. In contrast, gender differences in experience explain a relatively modest proportion of the gap (at most 8.2

\footnotetext{
${ }^{17}$ As before, we implement the bootstrap by sampling individuals (rather than observations) with replacement to take into account the interdependency of observations. As a result, we obtain standard errors that are smaller than using only one wave of data (reflecting the efficiency of pooling wages), but which are larger than treating each observation as independent.
}

per cent at the 25th percentile) despite our detailed measures of actual experience. In fact, differences in labour market experience contribute to reducing (rather than increasing) the wage gap among high-wage workers although this effect is not statistically significant. Similarly, education has an insignificant effect on the gender wage gap throughout the distribution, whereas demographic characteristics contribute significantly to the gap only in the top quarter of the distribution. ${ }^{18}$ Taken together, these results indicate that the distribution of relative wages in the public sector mainly reflects the relative labour market position of low-wage men and women and is largely unexplained by the wage-related characteristics of high-wage workers.

Introducing measures of occupation into the set of controls for labour market position has two effects (see the right panel of Table 2). First, the portion of the gender wage gap explained by relative labour market position falls substantially, particulary, at the bottom of the wage distribution. At the 10th percentile, for example, the component as a result of labour market position falls from 101.6 to 21.2 per cent. Second, the fall in the component as a result of labour market position, not surprisingly, translates into an increase in the unexplained component of the gender wage gap. At the median, for example, the unexplained component increases from 66.4 to 97.8 per cent when we include occupation into the model. The percentage of the gender wage gap accounted for by the other three factors remains roughly unchanged. Only at the 90th percentile does occupational segregation contribute to reducing the unexplained component of the gap. That the distribution of men and women across public-sector occupations appears to advantage, rather than disadvantage Australian women, is inconsistent with much of the international literature which suggests that labour market segregation contributes to the lower relative wages of women (see, e.g. Groshen, 1991; Blau \& Kahn, 2000; Dolado et al., 2002). These results are, however,

\footnotetext{
${ }^{18}$ In the parallel decomposition that reweights differences in conditional wage distributions by the distribution of male wage-related characteristics, we found that gender differences in education contribute to a significant reduction in the public-sector gender wage gap. Results are available upon request.
} 


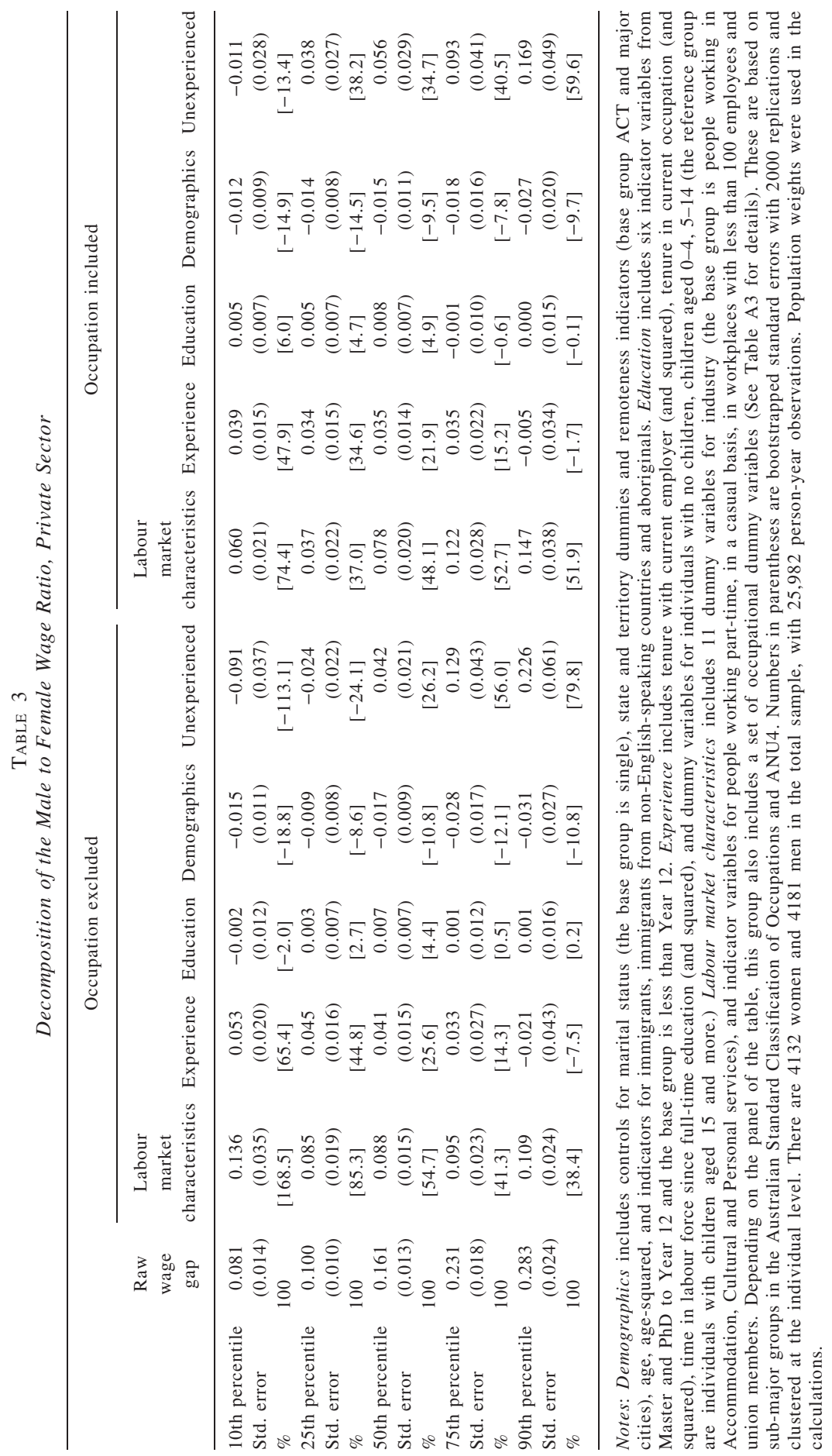


consistent with previous results based on Australian data (see Rimmer, 1991; Lee \& Miller, 2004; Kee, 2006).

Table 3 presents our decomposition results for the private sector. Unlike the public sector, the unconditional gender wage gap rises as the wage level increases, from 8.1 per cent at the 10 th percentile to 28.3 per cent at the 90 th percentile. Differences in the conditional wage distribution serve to reduce (rather than increase) the pay gap faced by women at the very bottom of the wage distribution. Gender differences in wage-related characteristics, in particular labour market position, fully account for the pay gap facing low-wage women, but explain less than half of the gender wage gap among high-wage workers. Consistent with the public-sector results, we find no evidence that employer discrimination is more prevalent among low-wage, private-sector employers than among their highwage counterparts. Thus, as before, the issue seems to be one of glass ceilings rather than sticky floors.

In sharp contrast to the public sector, gender differences in labour market experience are an important explanation for the lower relative wages of women employed in the private sector. At the median, for example, experience accounts for roughly a quarter of the gender wage gap. Only among the highest paid private-sector workers (at the 90th percentile) is no significant experience effect seen. At the same time, as in the public sector, gender differences in education and demographic characteristics are not significant in explaining the lower relative wages of women employed in the private sector. Interestingly, the effects of education and demographics are often of opposite signs in the two sectors; although given the imprecision of the estimates it is difficult to form firm conclusions about what this might imply. Finally, labour market position accounts for an economically important and statistically significant proportion of the gap across the wage distribution. The magnitude of the effect is roughly constant across the distribution and more than explains the gap at the bottom of the wage distribution where the relative wage gap is smaller. Still, at the 90th percentile, labour market position accounts for 38.4 per cent of the gap.

Introducing occupation into the set of controls for labour position has no substantive effect on the portion of the gender wage gap attributable to differences in experience, educational qualifications and demographic characteristics (see the right panel of Table 3). However, as was the case in the public sector, the portion of the gender wage gap explained by gender differences in labour market position falls substantially at the bottom of the wage distribution where the unconditional wage gap is smaller. Although labour market position continues to explain most of the the 8.1 per cent gender wage gap at the 10th percentile, the relative importance of labour market position falls by approximately 50 and 6 percentage points at the 25 th and 50th percentiles, respectively. There is a corresponding increase in the portion of the wage gap accounted for by differences in conditional wage distributions (i.e. estimated labour market discrimination) once occupational controls are added. At the median, for example, the unexplained component increases from 26.2 to 34.7 per cent. These effects are reversed in the top half of the wage distribution where gender differences in occupation contribute positively towards explaining the gender wage gap. At the 90th percentile, for example, the portion of the wage gap explained by labour market position increases (from 38.4 to 51.9 per cent), while the unexplained component falls (from 79.8 to 59.6 per cent) once occupational controls are included.

\section{Conclusions}

This article analyses the source of the gender wage gap in public- and private-sector employment in Australia. Our results suggest that, irrespective of the employment sector, the gender wage gap among low-paid workers is fully explained by gender differences in productivity-related characteristics. Among highwage workers, however, the wage gap faced by women is mostly (approximately 60 and 50 per cent) unexplained in the private and public sectors. Thus, our results are more consistent with the presence of glass ceilings than with sticky floors (Albrecht et al., 2003; Booth et al., 2003). Identification of the specific components of the gender wage gap reveals that disparity in educational qualifications and demographic characteristics are generally unimportant in explaining the wage gap, whereas differences in men's and women's labour market experience have a more important role in explaining relative private- than public-sector wages particularly for workers in the bottom 
half of the wage distribution. Finally, gender differences in labour market position (e.g. industry, casual, part-time, union membership) provide an important explanation for the relatively low wages received by women. However, taking occupational segregation into account serves to increase (rather than decrease) the unexplained component further for all but the most highly paid employees. Arulampalam et al.'s (2007) suggestion that inclusion of occupational controls provides a lower-bound estimate of the extent of labour market discrimination seems to be inappropriate in the Australian context where in most cases the occupational distribution favors women with respect to wages.

The fact that the magnitude (and source) of the gender wage gap varies across labour market sectors certainly supports the view that wage-setting mechanisms differ in public- and private-sector employment. Still, there are a number of puzzles yet to be resolved. In particular, the smaller wage gap in the public sector is consistent with more intensive anti-discrimination enforcement and faster occupational integration in public-sector employment (see Gregory \& Borland, 1999). However, almost none of the gap in the relative wages of highly paid, public-sector employees can be attributed to differences in their productivity-related characteristics. Why then do high-wage women employed in the Australian public sector continue to earn less than their male counterparts? To what extent is this evidence of employer discrimination? Moreover, it is not immediately obvious why gender differences in industry, casual status, part-time status and union membership play such a large role in explaining the gender wage gap for low-wage workers. Booth and Wood (2008) find, for example, that, unlike in the United States and the United Kingdom, part-time workers in Australia receive a wage premium rather than a wage penalty suggesting that it is not the concentration of women in part-time employment. Future research will be needed to carefully examine the role of labour market position in driving relative wages and to assess the extent to which labour market position itself might be the result of discriminatory factors. Finally, why does occupational segregation seem to improve rather than undermine the relative wages of women in Australia when then opposite appears to be the case in other countries? In their review of the literature, for example, Blau et al. (1998, p. 1) conclude that 'occupational segregation by sex has repeatedly been cited by scholars as a major determinant of the gender pay gap'. Yet, our results are consistent with previous findings that women's occupational position improves their relative wages throughout much of the distribution despite a relatively high degree of persistent occupational segregation. This leaves open a number of questions about the particular role of Australian labour market institutions in producing this result.

\section{REFERENCES}

Albrecht, J., Bjorklund, A. and Vroman, S. (2003), 'Is there a Glass Ceiling in Sweden?', Journal of Labor Economics 21, 145-77.

Amuedo-Dorantes, C. and De la Rica S. 'The Role of Segregation and Pay Structure on the Gender Wage Gap: Evidence from Matched Employer-Employee Data for Spain', Contributions to Economic Analysis \& Policy, (online journal) 2006; 5(1), article 10. [Cited 15 June 2008.] Available from: http://www.bepress.com/ bejeap/contributions.

Arulampalam, W. Booth, A. and Bryan, M. (2007), 'Is there a Glass Ceiling over Europe? Exploring the Gender Pay Gap across the Wages Distribution', Industrial \& Labor Relations Review, 60, $163-86$.

Australian Bureau of Statistics (1997), ASCO Australian Standard Classification of Occupations, 2nd edn. ABS, Canberra, Australia, Cat. No. 1220.0.

Australian Bureau of Statistics (2008), Consumer Price Index, Australia, March 2008. ABS, Canberra, Australia, Cat. No. 6401.0.

Blau, F.D. and Kahn, L.M. (1996), 'Wage Structure and Gender Earnings Differentials: An International Comparison'. Economica, 63, S29-62.

Blau, F.D. and Kahn, L.M. (2000), 'Gender Differences in Pay', Journal of Economic Perspectives, 14, 75-99.

Blau, F.D., Simpson, P. and Anderson, D. (1998), 'Continuing Progress? Trends in Occupational Segregation in the United States Over the 1970s and 1980s', National Bureau of Economic Research Working Paper 6716.

Booth, A.L. and Wood, M. (2008), 'Back-to-Front Down Under? Part-Time/Full-Time Wage Differentials in Australia', Industrial Relations, 47, 114-35.

Booth, A.L., Francesconi, M. and Frank, J. (2003), 'A Sticky Floors Model of Promotion, Pay and Gender', European Economic Review, 47, 295-322.

Borland, J. (1999), 'Earnings Inequality in Australia: Changes, Causes and Consequences', Economic Record, 75, 177-202. 
Breunig, R. and Rospabe, S. (2005), 'Parametric vs. Semi-Parametric Estimation of the Male-Female Wage Gap: An Application to France', Unpublished Working Paper, The Australian National University, Research School of Social Sciences (Economics Program), Canberra, Australia.

Buchinsky, M. (1998), 'Recent Advances in Quantile Regression Models: A Practical Guide for Empirical Research', Journal of Human Resources, 33, 88126.

Butcher, K.F. and DiNardo, J. (2002), 'The Immigrant and Native-Born Wage Distributions: Evidence from United States Censuses', Industrial \& Labor Relations Review, 56, 97-121.

Cobb-Clark, D.A. and Hildebrand, V. (2006), 'The Wealth of Mexican Americans', Journal of Human Resources, 41, 841-73.

DiNardo, J., Fortin, N.M. and Lemieux, T. (1996), 'Labor Market Institutions and the Distribution of Wages, 1973-1992: A Semiparametric Approach', Econometrica, 64, 1001-44.

Dolado, J.J., Felgueroso, F. and Jimeno, J.F. (2002), 'Recent Trends in Occupational Segregation by Gender: A Look Across the Atlantic', Institute for the Study of Labor Discussion Paper 524.

Donald, S.G., Green, D.A. and Paarsch, H.J. (2000), 'Differences in Wage Distributions between Canada and the United States: An Application of a Flexible Estimator of Distribution Functions in the Presence of Covariates', Review of Economic Studies, 67, 60933.

Eastough, K. and Miller, P.W. (2004), 'The Gender Wage Gap in Paid- and Self-Employment in Australia', Australian Economic Papers, 43, 25776.

Firpo, S., Fortin, N.M. and Lemieux, T. (2007), 'Unconditional Quantile Regressions', National Bureau of Economic Research Working Paper, 339.

Fortin, N.M. and Lemieux, T. (1998), 'Rank Regressions, Wage Distributions, and the Gender Gap', Journal of Human Resources, 33, 610-43.

Gracía, J., Hernández, P.J. and López-Nicolas, A. (2001), 'How Wide is the Gap? An Investigation of Gender Wage Differences Using Quantile Regression', Empirical Economics, 26, 146-67.

Gregory, R.G. and Borland, J. (1999), 'Recent Developments in Public Sector Labor Markets', in Ashenfelter, O. and Card, D.E. (eds), Handbook of Labor Economics Volume 3C, ch. 53. NorthHolland, New York; 3573-630.

Groshen, E.L. (1991), 'The Structure of the Female/ Male Wage Differential: Is it who you are, what you do or where you work?', Journal of Human Resources, 26, 457-72.

Gunderson, M. (1989), 'Male-Female Wage Differentials and Policy Responses', Journal of Economic Literature, 27, 46-72.
Haisken-DeNew, J.P. and Hahn, M. (2006), 'PanelWhiz: A Flexible Modularized Stata Interface for Accessing Large Scale Panel Data Sets'. [Cited 1 June 2008.] Available from: http://www.panelwhiz.eu

Jones, F.L. and McMillan, J. (2001), 'Scoring Occupational Categories for Social Research: A Review of Current Practice with Australian Examples', Work Employment and Society, 15, 539-63.

Juhn, C., Murphy, K.M. and Pierce, B. (1991), 'Accounting for the Slowdown in Black-White Wage Convergence', in Kosters, M. (ed.), Workers and their Wages. AEI Press, Washington, DC; 10743.

Kee, H.J. (2006), 'Glass Ceiling or Sticky Floor? Exploring the Australian Gender Pay Gap', Economic Record, 82, 408-27.

Kidd, M.P. (1993), 'Sex Discrimination and Occupational Segregation in the Australian Labour Market', Economic Record, 69, 44-55.

Kidd, M.P. and Shannon, M. (1996), 'The Gender Wage Gap: A Comparison of Australia and Canada', Industrial \& Labor Relations Review, 49, 72946.

Koenker, R. and Hallock, K.F. (2001), 'Quantile Regression', Journal of Economic Perspectives, 15, 143-56.

Kuhn, P. (1987), 'Sex Discrimination in Labor Markets: The Role of Statistical Evidence', American Economic Review, 77, 567-83.

Kunze, A. (2005), 'The Evolution of the Gender Wage Gap', Labour Economics, 12, 73-97.

Lee, Y. and Miller, P. (2004), 'Occupational Segregation on the Basis of Gender: The Role of EntryLevel Jobs', Australian Journal of Labour Economics, 7, 355-74.

Miller, P.W. (1987), 'The Wage Effect of the Occupational Segregation of Women in Britain', Economic Journal, 97, 885-96.

Miller, P. (2005), 'The Role of Gender among LowPaid and High-Paid Workers', Australian Economic Review, 38, 405-17.

Neumark, D. (1988), 'Employers' Discriminatory Behavior and the Estimation of Wage Discrimination', Journal of Human Resources, 23, 279-95.

Pfeifer, C. (2008), 'Risk Aversion and Sorting into Public Sector Employment', Institute for the Study of Labor Discussion Paper, 3503.

Rimmer, S.M. (1991), 'Occupational Segregation' Earnings Differentials and Status among Australian Workers', Economic Record, 67, 205-16.

Rummery, S. (1992), 'The Contribution of Intermittent Labor-Force Participation to the Gender Wage Differential', Economic Record, 68, 351-64.

Shapiro, D.M. and Stelcner, M. (1981), 'Male-Female Earnings Differentials and the Role of Language in Canada, Ontario, and Quebec, 1970', Canadian Journal of Economics, 14, 341-8. 
Appendix

TABLE A1

Descriptive Statistics by Sector and Gender

\begin{tabular}{|c|c|c|c|c|c|}
\hline \multirow[b]{2}{*}{ Variable } & \multirow{2}{*}{$\begin{array}{c}\text { Overall } \\
\text { mean }\end{array}$} & \multicolumn{2}{|c|}{ Public sector } & \multicolumn{2}{|c|}{ Private sector } \\
\hline & & Woman & Man & Woman & Man \\
\hline Wage per hour (dollars of 2001) & 20.1 & 21.0 & 23.8 & 17.2 & 20.8 \\
\hline \multicolumn{6}{|l|}{ Group: Demographics } \\
\hline \multicolumn{6}{|l|}{ Marital status } \\
\hline Married & 0.549 & 0.584 & 0.665 & 0.529 & 0.515 \\
\hline De facto & 0.135 & 0.133 & 0.128 & 0.140 & 0.134 \\
\hline Separated & 0.029 & 0.036 & 0.023 & 0.041 & 0.021 \\
\hline Divorced & 0.063 & 0.083 & 0.034 & 0.084 & 0.049 \\
\hline Widowed & 0.007 & 0.012 & 0.006 & 0.014 & 0.001 \\
\hline \multicolumn{6}{|l|}{ Geographical variables } \\
\hline New South Wales & 0.332 & 0.326 & 0.330 & 0.335 & 0.333 \\
\hline Victoria & 0.246 & 0.223 & 0.212 & 0.264 & 0.251 \\
\hline Queensland & 0.202 & 0.202 & 0.205 & 0.200 & 0.204 \\
\hline South Australia & 0.075 & 0.070 & 0.076 & 0.078 & 0.076 \\
\hline Western Australia & 0.093 & 0.091 & 0.086 & 0.087 & 0.099 \\
\hline Tasmania & 0.023 & 0.036 & 0.018 & 0.020 & 0.021 \\
\hline Northern Territory & 0.009 & 0.018 & 0.013 & 0.006 & 0.007 \\
\hline Inner region & 0.190 & 0.216 & 0.214 & 0.175 & 0.185 \\
\hline Outer region & 0.085 & 0.097 & 0.119 & 0.074 & 0.079 \\
\hline Remote region & 0.014 & 0.024 & 0.011 & 0.012 & 0.013 \\
\hline \multicolumn{6}{|l|}{ Other characteristics } \\
\hline Immigrant non-English background & 0.157 & 0.103 & 0.094 & 0.192 & 0.172 \\
\hline Immigrant & 0.259 & 0.197 & 0.202 & 0.295 & 0.274 \\
\hline Aboriginal or Torres Strait Islander & 0.013 & 0.020 & 0.014 & 0.013 & 0.011 \\
\hline Age & 39.0 & 41.1 & 42.1 & 38.2 & 37.8 \\
\hline \multicolumn{6}{|l|}{ Group: Education } \\
\hline Master or $\mathrm{PhD}$ & 0.038 & 0.066 & 0.100 & 0.016 & 0.025 \\
\hline Graduate certificate & 0.056 & 0.126 & 0.107 & 0.035 & 0.031 \\
\hline Bachelor degree & 0.165 & 0.266 & 0.185 & 0.146 & 0.136 \\
\hline Diploma & 0.098 & 0.115 & 0.127 & 0.104 & 0.079 \\
\hline Certificate & 0.242 & 0.128 & 0.260 & 0.168 & 0.329 \\
\hline Year 12 & 0.153 & 0.114 & 0.096 & 0.201 & 0.150 \\
\hline \multicolumn{6}{|l|}{ Group: Experience } \\
\hline Tenure with current employer & 6.5 & 8.5 & 11.7 & 4.6 & 5.6 \\
\hline Tenure in current occupation & 9.0 & 10.2 & 11.4 & 7.2 & 9.0 \\
\hline Children aged $0-4$ in household & 0.152 & 0.112 & 0.162 & 0.125 & 0.182 \\
\hline Children aged 5-14 in household & 0.283 & 0.298 & 0.302 & 0.275 & 0.277 \\
\hline No children & 0.377 & 0.320 & 0.337 & 0.359 & 0.423 \\
\hline Time in labour force since full-time education & 19.1 & 19.3 & 23.2 & 16.7 & 19.4 \\
\hline \multicolumn{6}{|l|}{ Group: Labour market characteristics } \\
\hline Part-time & 0.241 & 0.390 & 0.086 & 0.445 & 0.090 \\
\hline Casual & 0.205 & 0.131 & 0.064 & 0.329 & 0.185 \\
\hline Firm has less than 100 employees & 0.378 & 0.143 & 0.113 & 0.498 & 0.457 \\
\hline Union member & 0.316 & 0.517 & 0.601 & 0.179 & 0.254 \\
\hline
\end{tabular}

Notes: Information is from the Household, Income and Labour Dynamics in Australia survey waves 1-6. The sample includes employees aged 22-60 years. Boldface text indicate specific wage covariates considered in the decompositions. The base group in the Demographics group are individuals who are single, living in the ACT, in a major city, who are not immigrants nor aboriginal. In the Education group the base group is people who have less than year 12 education. In the Experience group the base group is individuals with children aged 15 and more. In the Labour market characteristics the base group is people working in accommodation, cultural and personal services and whose occupation is a labourer or a related worker. The Labour market characteristics group also includes 11 industry dummies; in every case the base group is people in accommodation, cultural, and personal services. There are 4132 women and 4181 men in the sample. Population weights were used in the calculations. 
TABle A2

Public Sector Occupations Used in the Analysis, Based on Australian Standard Classification of Occupations ASCO Sub-Major Groups and ANU4

\begin{tabular}{|c|c|}
\hline Number & Public sector \\
\hline 1 & Generalist managers (11) \\
\hline 2 & Sales and marketing managers and engineering and process managers \\
\hline 3 & Resource managers \\
\hline 4 & Other specialist managers \\
\hline 5 & Science, building and engineering professionals (21) \\
\hline 6 & Sales and related professionals; human resource professionals \\
\hline 7 & Business and organisation analysts \\
\hline 8 & Computing professionals \\
\hline 9 & Other business professionals \\
\hline 10 & Accountants and related professionals \\
\hline 11 & Nursing professionals and other health professionals (lower) \\
\hline 12 & Other health professionals (higher) and medical practitioners \\
\hline 13 & Other education professionals (lower) and (higher) \\
\hline 14 & Primary school teachers \\
\hline 15 & Secondary school teachers \\
\hline 16 & University teachers \\
\hline 17 & Other professionals (lower) and social welfare professionals \\
\hline 18 & Other professionals (higher) \\
\hline 19 & Other health professionals (higher) and legal professionals \\
\hline 20 & Science, engineering and related associate professionals (31) \\
\hline 21 & Office managers; real-state associate professors; computer support technicians \\
\hline 22 & Other business associate professionals; finance associate professionals \\
\hline 23 & Managing supervisors (sales and service) (33) \\
\hline 24 & Health and welfare associate professionals (34) \\
\hline 25 & Police officers \\
\hline 26 & Other associate professionals \\
\hline 27 & Combined with intermediate production and transport workers $(71,72,73,79)$ \\
\hline 28 & Advanced clerical and service workers $(51,59)$ \\
\hline 29 & $\begin{array}{l}\text { Other intermediate sales workers, receptionists; stock and purchasing clerks; } \\
\text { car and delivery drivers; bank workers }\end{array}$ \\
\hline 30 & General clerks \\
\hline 31 & Other numerical clerks; inquiry and admission clerks \\
\hline 32 & Sales representatives; accounting clerks \\
\hline 33 & Other intermediate clerk workers \\
\hline 34 & Personal care and nursing assistants; bar attendants \\
\hline 35 & $\begin{array}{l}\text { Education aides; other intermediate services (lower); children's care workers; } \\
\text { special care workers }\end{array}$ \\
\hline 36 & Other intermediate service workers (higher) \\
\hline 37 & Elementary clerks $(81)$ \\
\hline 38 & Elementary sales workers (82) and elementary service workers (83) \\
\hline 39 & Cleaners $(91)$ \\
\hline 40 & Factory labourers (92) and other labourers and related workers (99) \\
\hline
\end{tabular}

Notes: Numbers in parentheses are sub-major group codes in the ASCO, second edition (Australian Bureau of Statistics, 1997). Occupations with no number in parentheses come from combining ASCO2 and ANU4. 
TABLE A3

Private Sector Occupations Used in the Analysis, Based on Australian Standard Classification of Occupations (ASCO) Sub-Major Groups and ANU4

\begin{tabular}{|c|c|}
\hline Number & Private sector \\
\hline 1 & Generalist managers (11) \\
\hline 2 & Sales and marketing managers \\
\hline 3 & Engineering and process managers \\
\hline 4 & Resource managers \\
\hline 5 & Other specialist managers \\
\hline 6 & Other science and engineering professionals; architects and related professionals; engineers \\
\hline 7 & Natural science professionals \\
\hline 8 & Sales and related professionals \\
\hline 9 & Human resource professionals \\
\hline 10 & Business and organisation analysts \\
\hline 11 & Computing professionals \\
\hline 12 & Other business professionals; accountants and related professionals \\
\hline 13 & Nursing professionals; other health professionals (lower) \\
\hline 14 & Other health professionals (higher); medical practitioners \\
\hline 15 & Education professionals (24) \\
\hline 16 & Other professionals; social welfare professionals \\
\hline 17 & Other professionals (higher); other health professionals (higher) \\
\hline 18 & Legal professionals \\
\hline 19 & Medical and science technical officers \\
\hline 20 & Building associate professionals \\
\hline 21 & Office managers \\
\hline 22 & Real-estate associate professionals \\
\hline 23 & Computing support technicians \\
\hline 24 & Other business associate professionals \\
\hline 25 & Finance associate professionals \\
\hline 26 & Chefs; restaurant and catering managers; other hospitality managers \\
\hline 27 & Shop managers \\
\hline 28 & Other sales and service managers, supervisors \\
\hline 29 & Health and welfare associate professionals (34) and other associate professionals (39) \\
\hline 30 & $\begin{array}{l}\text { Mechanical and fabrication engineering (41), automotive (42), electrical and electronics (43) and } \\
\text { construction tradespersons (44) }\end{array}$ \\
\hline 31 & Food tradespersons $(45)$ \\
\hline 32 & Skilled agricultural and horticultural workers (46) \\
\hline 33 & Other tradespersons (lower); wood tradesperson; hairdressers \\
\hline 34 & Printing tradesperson; other tradespersons (higher) \\
\hline 35 & Advanced clerical and service workers $(51,59)$ \\
\hline 36 & Receptionists; car and delivery drivers \\
\hline 37 & Stock and purchasing clerks \\
\hline 38 & Other recording and dispatching clerks \\
\hline 39 & General clerks; other numerical clerks \\
\hline 40 & Inquiry and admissions clerk \\
\hline 41 & Accounting clerks \\
\hline 42 & Other intermediate clerical workers \\
\hline 43 & Other intermediate sales workers \\
\hline 44 & Sales representatives \\
\hline 45 & Personal care and nursing assistance; bar attendants \\
\hline 46 & $\begin{array}{l}\text { Education aides; other intermediate service workers (lower); children's care workers; special } \\
\text { care workers }\end{array}$ \\
\hline 47 & Waiters \\
\hline 48 & Other intermediate service workers \\
\hline 49 & Intermediate plant operators (71) and intermediate machine operators (72) \\
\hline 50 & Road and rail transport drivers (73) \\
\hline 51 & Storeperson \\
\hline
\end{tabular}


TABLE A3

(Continued)

\begin{tabular}{ll}
\hline Number & \multicolumn{1}{c}{ Private sector } \\
\hline 52 & Other intermediate production and transport workers \\
53 & Elementary clerks (81) \\
54 & Checkout operators and cashiers \\
55 & Sales assistants \\
56 & Other elementary sales workers \\
57 & Elementary service workers $(83)$ \\
58 & Cleaners (91) \\
59 & Product packagers \\
60 & Factory labourers \\
61 & Agricultural and related labourers \\
62 & Mining, construction and related labourers (lower and higher) \\
63 & Kitchenhands \\
64 & Miscellaneous labourers \\
\hline
\end{tabular}

Notes: Numbers in parentheses are sub-major group codes in the ASCO, second edition (Australian Bureau of Staistics, 1997). Occupations with no number in parentheses come from combining ASCO2 and ANU4. 